\title{
Editorial Notice
}

Professor W. B. Thompson has retired from the position of Associate Editor of the Journal with effect from 31 December 1990. Our readers and authors will all wish to join me in expressing our thanks to Bill for his work in that position, which began at the very inception of the Journal.

It is hoped to expand the team of Associate Editors in the near future.

\section{J. P. Dougherty}

